\title{
Automation of Agricultural Irrigation System with Open Source
}

\author{
Bladimir Jaime Pérez Quezada and Javier Fernández \\ Faculty of Computer Science, Electronics and Communication, \\ Universidad de Panamá, Panamá \\ bladimir.perezq@gmail.com, \\ fernanj@yahoo.com
}

\begin{abstract}
In this present job, we seek to develop a prototype of an automated agricultural irrigation system, monitored and controlled remotely. For that, we will use inexpensive tools, flexibility and support such as Arduino, XBee and Android. Arduino and XBee, will be responsible of the automating the system. Android will achieve the remote monitoring and control from anywhere in the world where there is cellular service and Internet. In this way we can give the farmer the comfort and security that he don't get with a manually controlled system.
\end{abstract}

Keywords: Arduino, ADK, Android, XBee.

\section{Introduction}

At present irrigation systems, the vast majority are operated manually, requiring close attention of the farmer. Basically the farmer decides with your experience, the period and the moment to watering the crop. Because of this, will can have common problems caused by humans, such as forget turn on and turn off the system at the time considered. This causes direct problems with the crop such as, excess of water in the crop or drying by lack thereof, in addition to a higher energy consumption of the system and higher consumption of water resources that is as important to national and international level. All this lowers productivity, causing economic losses to farmers. Having an automated system, we seek to resolve these errors, increasing production, save on energy consumption and minimize the decline in productivity, as the farmer will not has that stay aware constantly of the cultivation, because the system will be Stringer and it will take the required decisions [2].

\section{Methods and Materials}

To develop our agricultural irrigation we focus on aspects such as: open source, scalability, open to future research and implementations. The tools used in our research are: 
- Arduino Mega ADK. Integrates one USB host that work directly with Android devices and it will be responsible of take the decisions pertinent of the irrigation system.

- Android. Will show the details of the system to the user and serve as link to the Internet to upload data to the cloud system of Google Drive.

- XBee. Modem based on ZigBee wireless communication protocol. Developed and backed by the company Digi International. Will maintain communication with the Arduino Mega ADK, sending the soil moisture data.

- Soil Moisture Sensor. Soil moisture sensor of resistive type, whose operating principle is based on the conductivity, which will vary depending on the moisture present in the soil [1].

\section{$3 \quad$ Expected Results}

Get an agricultural irrigation system low cost, that can be implemented in real crops, offering the water required by cultivation. That the user has the same monitoring both on the site as remotely via the Internet through a computer or mobile device. Furthermore, the user can control the system remotely via SMS, as shown in Figure 1.

With this research, we want to help the farmer get a better production and minimize waste.

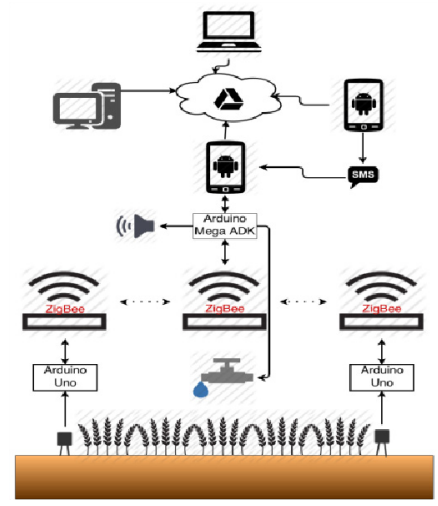

Fig. 1. Functional diagram of the system

\section{References}

1. Schugurensky, C., Capraro, F.: Control Automático de Riego Agrícola con Sensores Capacitivos de Humedad de Suelo, aplicaciones en Vid y Olivo, Universidad Nacional de San Juan, Argentina. Instituto de Automática, INAUT (2007)

2. Varela, R.V., Rivas, C.R., Aréchiga, R.S.: Automatización de un sistema de riego. Revista Digital de la Universidad Autónoma de Zacatecas, Universidad Autónoma de Zacatecas, Enero, Abril. Unidad Académica de Ingeniería Eléctrica (2007) 